\title{
Ulcerative colitis: A review on drug delivery strategies
}

\author{
El Bethel Lalthavel Hmar, Sujata Paul, James H. Zothantluanga, Hemanta Kumar Sharma* \\ Department of Pharmaceutical Sciences, Faculty of Science and Engineering, Dibrugarh University, Dibrugarh 786004, Assam, India
}

\begin{abstract}
Ulcerative colitis is one of the two major forms of inflammatory bowel disease which has unforeseeable clinical course, marked by a chronic inflammation of the colon and remission of the disease. The treatment of Ulcerative colitis is managed by the administration of anti-inflammatory or immunosuppressive drugs that are ingested orally. However, the efficacy of the drug via oral route remains unclear as the release of drugs takes place in the upper gastrointestinal tract that allows inadequate amount of drug release to the colon thereby causing various adverse effects. Therefore, the advancement of disease targeted drug delivery strategies offers numerous gains over non-targeting by granting more effective therapy and diminishing the systemic adverse effect. In this review, we investigate and discuss various approaches that assist in targeting mechanism of the respective drugs to the colon for the hindrance and management of colonic ailments.
\end{abstract}

Keywords: Biodegradable polymers, colon targeted drug delivery system, delivery strategies, inflammatory bowel disease, ulcerative colitis.

\section{Introduction}

Ulcerative colitis (UC) is a long-standing disorder that causes chronic inflammation in the gastrointestinal (GI) tract. It usually involves the rectum at the initial stage and gradually extend to affect the entire colon. ${ }^{1}$ It is characterized by blood stool, mucus diarrhea, reduced appetite, tenesmus, bowel distension, anemia and also by relapsing and remitting course. More than $50 \%$ of UC patients experience at least one relapse during a time period of 10 years wherein $80 \%$ are mild to moderate, and $20 \%$ are oppressive. However, the severity of the disease depends upon the duration of the disease. ${ }^{2}$ The etiology of UC remains obscure and may affect people of any age group., ${ }^{2,3}$ Researchers have presumed multiple factors to be involved in provoking the disease viz. lifestyle, oxidative damage, environment, genes, diet, microbiota and others thereby resulting in dysregulation of immunological responses. ${ }^{4-6}$

$U C$ is classified depending on the severity of the disease and where inflammation occurs in the colonic region. Such types are: (i) ulcerative proctitis (UP) which is the initial manifestation and mild form of UC that affects the rectum only, (ii) left-sided colitis or distal colonic disease (L-UC) in which inflammation extends from the rectum up the colon (left) distal to the splenic flexure and (iii) extensive colitis or pancolitis which is the continuous mucosal inflammation extending from the rectum up to the caecum or proximal ascending colon. ${ }^{7-11}$ UC associated colo-rectal cancer (CRC) is another serious and deadly complications of UC. ${ }^{12}$ The risk of 
developing CRC is impacted by the onset of inflammatory bowel disease (IBD) at younger age, long duration of the disease, primary sclerosing cholangitis, dysplasia, pseudopolyps and genetic modifications. ${ }^{8,13}$ Several diagnostic features, clinical data and laboratory markers are employed for the diagnostic purpose of UC that control the selection of proper treatments and for forecasting the patient's prognosis. $^{14,15}$

Surveillance studies have shown amino-salicylates and its derivatives to be most successful for induction and maintenance therapy of UC. Use of corticosteroids and other drug have been implicated as an alternative or if the patient do not show any sort of response. ${ }^{16,17}$ However, immunomodulators and corticosteroids are not the treatment of choice due to their immoderate side effects on long-term use; hence, amino-salicylates remain to be the treatment of choice. ${ }^{18-20}$ The existing formulation which is taken by mouth as a therapy has shown affirmative results in majority of the UC patients but the administered drug easily gets absorbed in the upper GI tract resulting with some drawbacks such as increased risk of the systemic adverse drug reaction, patient incompliance, difficult dosing regimens, first pass metabolism, reduced its potential of therapeutic success and complication in gastric retention time. ${ }^{21-23}$ To overcome such challenges, colon targeted delivery system (CTDS) has been opted by the researchers for successful targeting of drugs to the specific region thereby protecting the drug from degradation, its release in the upper $\mathrm{Gl}$ tract and maintaining the symptoms, predicting, treating complications, remission and reducing mortality due to UC. ${ }^{24,25}$

\section{Colon targeted drug delivery system (CTDDS)}

The importance of colonic drug delivery has increased due to advances in systemic delivery of therapeutic peptides, proteins, antidiabetic agents, anti-asthmatic and antihypertensive drugs. ${ }^{26}$ Protection of the drug, i.e. inhibiting the release of drug and degradation of the bioactive agent from the delivery system while it is en route for colon is a must have property essential for colon specific drug delivery system (CSDDS). ${ }^{27}$ Formulation factors, retention time and the extent of retrograde spreading are few of the notable factors influencing the concentration of drug to reach the colon. ${ }^{28}$ To maximize the efficacy and reduce the adverse effects of drugs for long-term management of ulcerative colitis, therapeutic agents may be administered via CTDDS. $^{29}$ The use of $\mathrm{pH}$-sensitive polymer, bacterial degrading coating material, biodegradable polymer matrix, time-dependent formulation, pro-drug and hydro gels are some of the approaches utilized for CTDDS. ${ }^{30}$ Table 1 highlights the advantages and disadvantages for CTDDS.

\section{Choice of polymers used for achieving colonic delivery}

Biodegradable polymers are used as a carrier for colon targeting due to their least toxicity, superior biocompatibility with the Gl environment, degradability in specific colonic $\mathrm{pH}$ and site specificity due to biodegradable enzymes present in colon. ${ }^{42,43}$ Further, these polymers are grouped into (i) natural polymer and (ii) synthetic polymers, and these polymers belong to the polysaccharides and polyesters family. ${ }^{42}$ Table 2 is a list of the biodegradable polymers used for colon targeted drug delivery. Figure 1 represents the oral drug delivery targeting the colon.

\section{Selective approaches and carriers used for successful colon targeting}

\section{Conventional approaches for colon targeting}

\section{Pro-drug approach}

For colon specific delivery, the effectiveness of potential drugs can be improved for its pharmacodynamic and pharmacokinetic properties by developing it as a pro-drug wherein the covalent linkage between the pro-moiety and drug molecule may act as a diagnostic feature to aid in identification of pro-drugs. ${ }^{63,64}$ Pro-drugs are intended to undergo biotransformation thereby releasing the active drug molecule only in the colon.

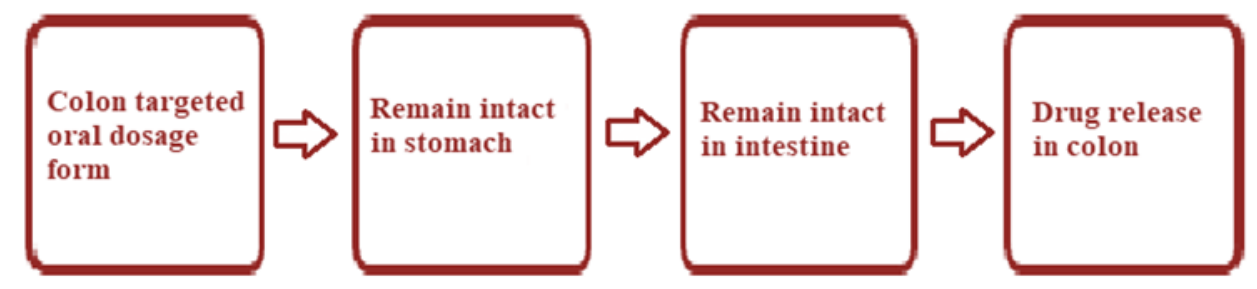

Figure 1 | Schematic diagram representing oral drug delivery targeting the colon. 
Table 1 | Advantages and disadvantages of colon targeted drug delivery system (CTDDS)

\begin{tabular}{ll}
\hline Advantages & Disadvantages $\mathbf{7 2 , 2 2 , 3 4 , 3 7 , 3 8 , 3 9 , 4 0}$ \\
\hline Avoid first pass metabolism & Drug release may be insufficient \\
\hline Dosing frequency, toxicity and cost is reduced & Manufacturing process may be difficult \\
\hline Effects are localized in the colon & $\begin{array}{l}\text { Manufacturing defects may negatively affect drug } \\
\text { action }\end{array}$ \\
\hline Gastric irritation is reduced & $\begin{array}{l}\text { Unusual gastric physiology and colonic bacterial } \\
\text { enzymes may decrease its bioavailability and } \\
\text { effectiveness respectively }\end{array}$ \\
\hline Retention time is increased & $\begin{array}{l}\text { Decreased stability due to non-specific drug } \\
\text { interaction with colonic contents }\end{array}$ \\
\hline Adverse drug interactions are minimized & $\begin{array}{l}\text { Require site specific dosage form for optimum } \\
\text { activity }\end{array}$ \\
\hline $\begin{array}{l}\text { Lesser peptidase activity in colon allows delivery of } \\
\text { peptides, insulin and growth hormones }\end{array}$ & $\begin{array}{l}\text { Viscous colonic contents reduce the availability of } \\
\text { drugs to absorptive membrane }\end{array}$ \\
\hline Localized and systemic drug delivery is achievable & \\
\hline $\begin{array}{l}\text { Chemical and enzymatic degradation in the upper } \\
\text { Gl tract is avoided }\end{array}$ & \\
\hline
\end{tabular}

The activation of pro-drug may be dependent on $\mathrm{pH}$, micro flora and distinct enzymes (glucuronidase, azoreductase, esterase, glycosidase, cyclodextranase, dextranase, and nitroreductase) present in the colon. Azo-containing pro-drug like olsalazine, ipsalazide, sulfasalazine and balsalazide were engineered to treat inflammatory bowel disease (IBD) by developing it to undergo biotransformation only after reaching colon. ${ }^{65-67}$

Bacterial metabolic processes like the azo compounds which is metabolized by intestinal bacteria is regarded among the most extensively studied processes. Such example is the reduction of a prodrug named sulfasalazine into sulfapyridine and 5-aminosalicylic acid (5-ASA) by colonic azoreductases. ${ }^{25,68}$ However, complete absorption of sulfapyridine (carrier moiety) through the colon causes adverse effects such as blood dyscrasia, hypersensitivity, hepatitis, hepatic failure, impotency, leukopenia, agranulocytosis, hemolyticanemia, cyanosis and thrombocytopenia. ${ }^{69}$ Incorporation of lipid pro-drugs which consists of a covalently bound drug and lipid moiety (steroid, fatty acid, phospholipid, triglyceride) into the metabolic pathways enables the crossing of barriers in the body easily. ${ }^{70,71}$ Covalent azo linkages between 5amino-salicylates (5-ASA) and carrier molecules are most common pro-drugs used in IBD. Other examples include glucuronide, glycoside, amino acids, dextran, and cyclodextrin. ${ }^{67,72}$

\section{Polysaccharide based delivery system}

Polysaccharides that are selectively digested by the colonic bacteria give additional option for colon targeting of drugs. ${ }^{3}$ Polysaccharide polymers are biodegradable polymeric carbohydrate molecules found in all living organisms. With their structures ranging from linear to highly branched structures, long chains of monosaccharide units covalently bounded together by glycosidic linkages make up the polymer. ${ }^{73}$ Animal polysaccharides include chitin and chondroitin sulphate while plant polysaccharides include cellulose, hemicellulose, starch, hyaluronic acids, guar gum and alginate. ${ }^{41,73}$ Polysaccharides are predominantly metabolized by colonic bacteria where they are broken down to simple saccharides by saccharolytic species like Bifidobacteria and Bacteroides consequently the entrapped drug is released. As denser cross linking slows down drug release, the rate of drug release may be influenced by the cross-linking density of the polymer and are considered safe for use. ${ }^{25,74,75}$ Additional advantages include large-scale availability, low cost, less toxicity and greater biocompatibility.

Amoebiasis, IBD, ulcerative colitis, Crohn's disease or colorectal cancer may be effectively treated with colon targeting polysaccharide-based micro/ nanocarriers. $^{76,77}$ Theranostics with improved therapeutic efficacy and safety is likely to be in existence with advancing polysaccharide-based nano materials with multifunctional and better controlled release systems (CRS's). ${ }^{75,78}$ As polysaccharides like guar gum, pectin and amylase are metabolized in the presence of Bifidobacterium, Lactobacillus and Saccharomyces, co-administration with probiotics 


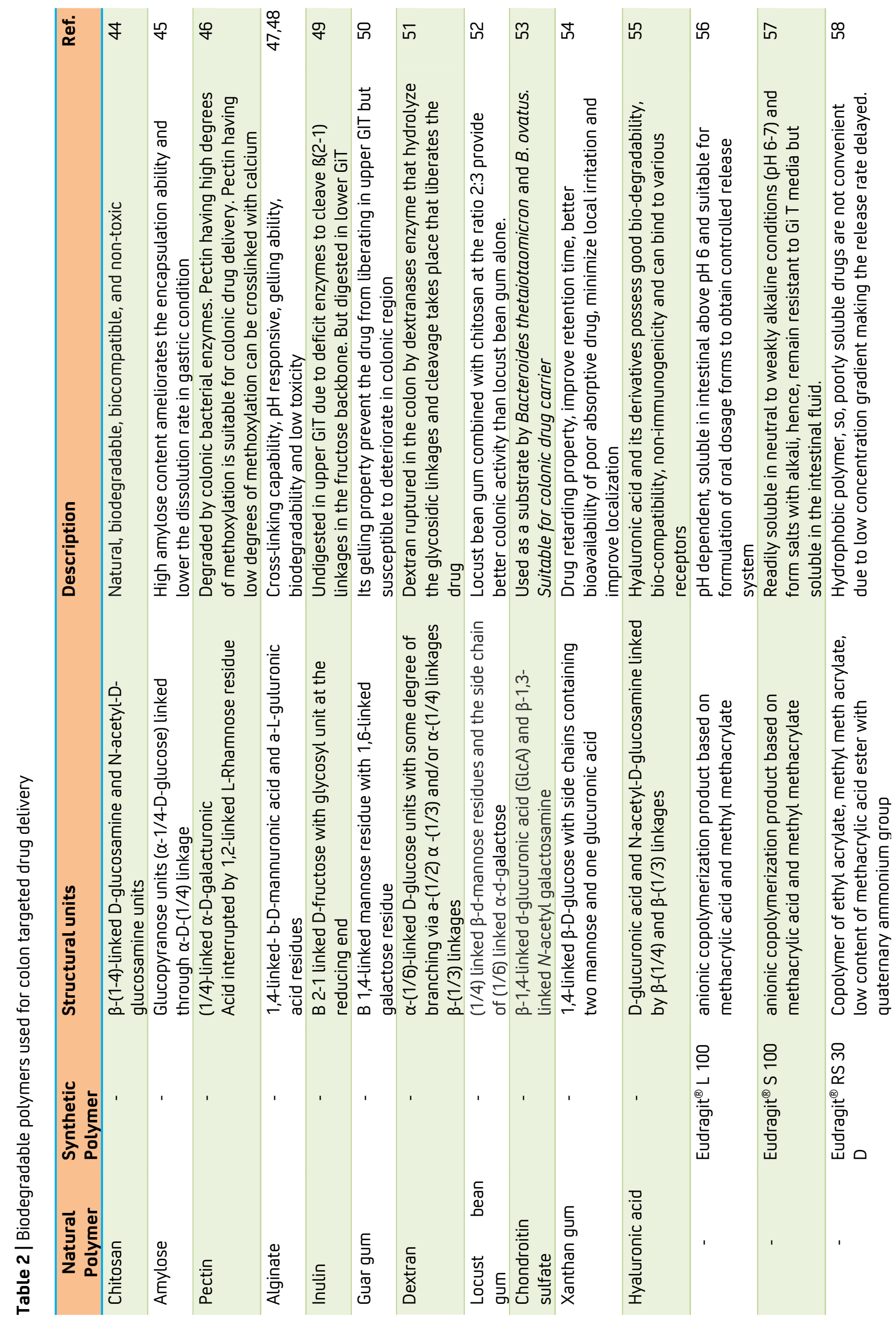




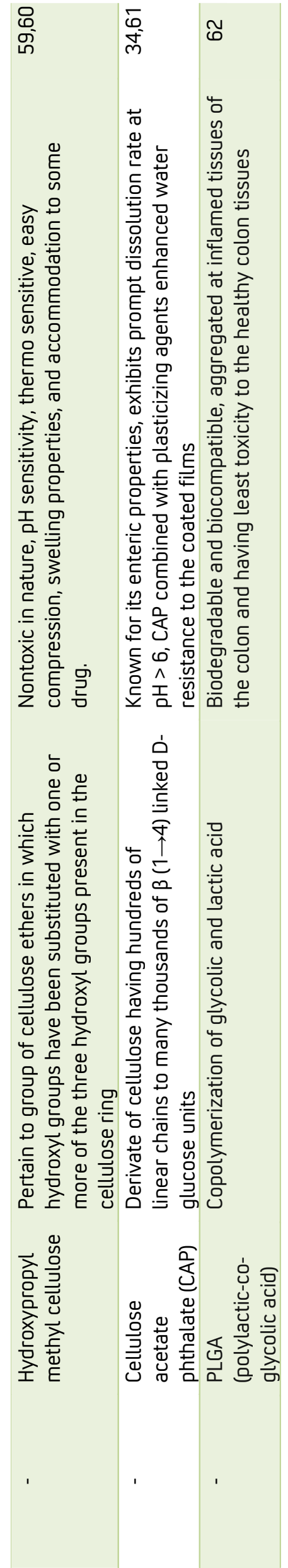

may aid in restoration of normal micro flora along with their targeted release in colon. ${ }^{79,80}$

\section{Ligand/receptor mediated delivery system}

During the inflammatory process, the receptors get overexposed on the cell surfaces. ${ }^{81,82}$ The ligands used in designing ligand/receptor mediated delivery system are selected by considering their functional expression profiles of the individual proteins/ receptors at the target cells/organs. Some of such ligands are antibodies, peptides, folic acid, hyaluronic acid, etc. ${ }^{71}$ Two of them are mentioned below:

Antibodies. Harel et al. designed and developed anti-transferrin receptor antibody-conjugated liposomes, proving better targeting mucosal inflammation than unconjugated liposomes. ${ }^{83}$ Xiao et al. also developed an orally delivered SCCD98functionalized siCD98 loaded nanoparticles for IBD therapy. The scCD98-functionalized nanoparticles reduce expression of this protein by colonic epithelial cells, macrophages; and exhibited a high affinity for CD98-overexpressed cells. ${ }^{84}$

Peptides. Peptide includes many advantages like biocompatibility, cost-effectiveness, chemical diversity, and stimuli responsiveness, so, gained enormous concern as a potential ligand for delivery of drugs to the targeted site. ${ }^{85}$ Due to large binding interfaces with receptors, peptides exhibit higher binding affinity and specificity compared to small molecule ligands. Ren et al. conducted an investigation on the application of synthesized 12residue peptide (tyrosine kinase or TK) that interacts with integrin $\alpha_{6} \beta_{1}$ for the colon-specific delivery of anticancer drugs. TK peptide increases the uptake of human epithelial cell line (Caco-2) and also increase the penetration of the tumorspheroids. ${ }^{86}$

\section{pH-dependent delivery system}

Local drug delivery to the colon as available in majority of commercial-ized systems depend on altered $\mathrm{pH}^{87}$ The neutral $\mathrm{pH}$ and prolonged transit time of colon offer various therapeutic advantages as a site of drug delivery. ${ }^{41}$ Using $\mathrm{pH}$-dependent polymers such as CAT (cellulose acetate phthalate), CAP(cellulose acetate phthalates), HPMCP 50 and 55 (hydroxypropylmethyl cellulosephthalate), Eudragit L (copolymers of methacrylic acid and methacrylate), Eudragit FS, Eudragit S 100 and Eudragit P4135 F which react to the elevated $\mathrm{pH}(\geq 6.8)$, the colontargeted drug delivery systems are designed. ${ }^{71,88,89}$ The dosage form is required to pass through altering $\mathrm{pH}$ environments of different anatomical regions of Gl tract like stomach ( $\mathrm{pH} 1.5-3.5)$, duodenum $(\mathrm{pH} 6)$, jejunum and ileum (pH 5.5-6.8), and caecum $(\mathrm{pH} 6.8$ -7.3 ) before reaching colon $\mathrm{pH} 6.4$ in ascending 
colon, $\mathrm{pH} 7.0$ in descending colon). ${ }^{76}$

Dosage forms coated with $\mathrm{pH}$-dependent enteric polymers protect the drug from the acidic stomach but the coating starts to dissolve as $\mathrm{pH}$ moves towards alkaline in small intestine and ultimately the drug releases in the colonic $\mathrm{pH}^{74}$ In diseased state, the $\mathrm{pH}$ and transit time can vary causing premature release or no release at all. ${ }^{90}$ There are however, certain problems linked with this approach. ${ }^{3}$ Attempts have been made to collaboratively utilized $\mathrm{pH}$-dependent systems with enzyme-triggered systems and time-dependent systems. ${ }^{11}$ Fahima et al. prepared prednisolone loaded microsphere by combining $\mathrm{pH}$ and time - dependent polymers (Eudragit ${ }^{\otimes}$ S-100 (ES100) and ethyl cellulose (EC)) for colon targeting delivery system then evaluated and reported that the selected microsphere is able to deliver the drug to the colon thereby preventing the release of drug in the upper GiT. ${ }^{91}$ Akhgari et al. prepared and evaluated indomethacin pellets loaded with the combination of $\mathrm{pH}$-dependent and timedependent polymers for colonic delivery and revealed that it is effective and desirable for sustained drug release in the colonic region. ${ }^{92}$

\section{Time release system}

Drug delivery systems that are time dependent are based on the principle that drug release is prevented until it reaches the colon. ${ }^{93}$ The transit time of GIT influences the site of preliminary drug release in case of time-dependent systems. Under normal physiological environment, the average transit time ranges from 2-6 hours. The transit time is shortened in IBD patients due to pathophysiological alterations. In IBD, diarrhea affects the transit time as peristaltic movement is accelerated leading to inaccurate prediction for the arrival time of the dosage form to the colon and may even lead to poor dosage availability. The colonic transit time in ulcerative colitis is 9.5-39.1 hours whereas in healthy individuals, it ranges from 41.162.3 hours. $^{89,94}$

Knowledge on the dosage and gastric transit time is a prerequisite for successfully drug delivery. For non-disintegrating single dosage form, the gastric emptying time ranges from 15 to 180 minutes. For small intestine, it varies lies between 3-4 hours. The average transit time in the colon for women and men is 47 hours and 33 hours respectively. Overcoming the large variation observed in gastric emptying is achieved by enteric coating in most of these systems. To improve the efficacy and accuracy of drug release, time dependent system is coupled with $\mathrm{pH}$-dependent drug release and time controlled drug release. ${ }^{95,96}$

For colon-targeted drug delivery, a promising

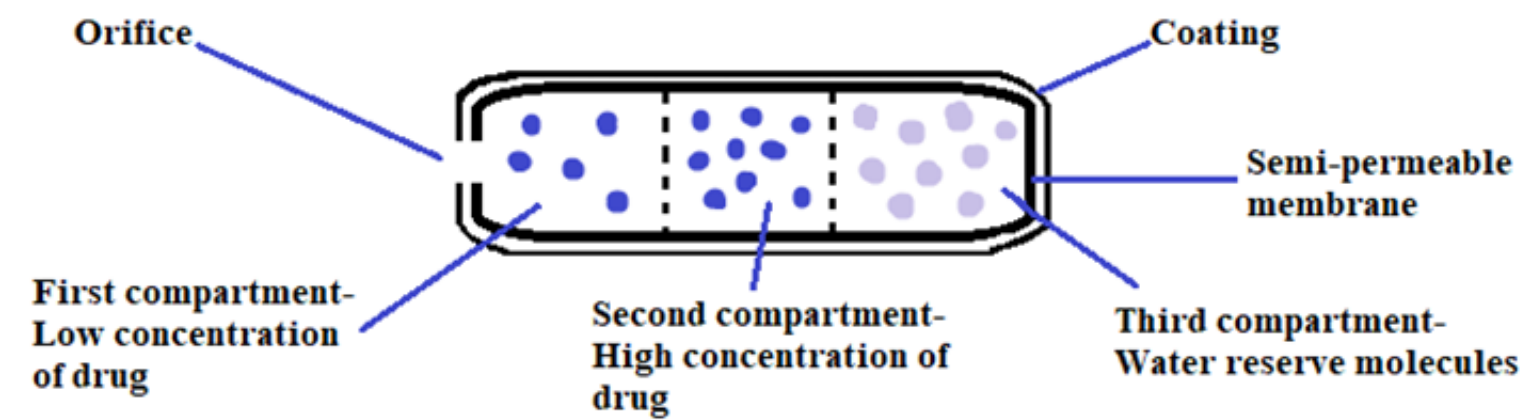

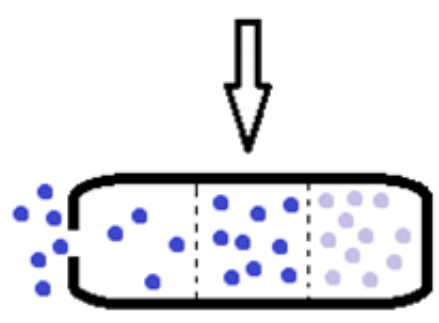

Coating releases
mini-burst of drug

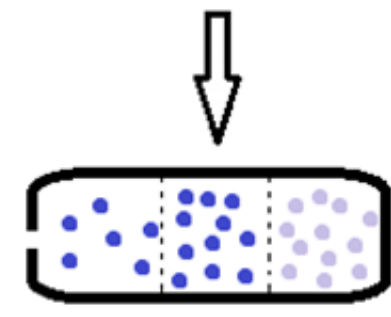

Diffusion releases drug from first compartment

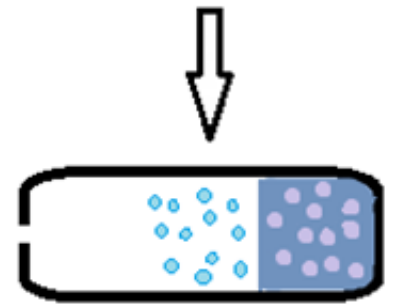

Osmotic pressure releases drug from second compartment when water enters and reacts with third compartment

Figure 2 | Process flow diagram of OROS-CT colon targeted drug delivery system. 
controlled release carrier was formulated by ElGibaly et al. Zn pectinate gel (ZPG) microparticles was loaded with ketoprofen in addition with pectinate microparticles (2-3\% $\mathrm{w} / \mathrm{v}$ pectin, $2.75 \% \mathrm{w} / \mathrm{v}$ $\mathrm{Zn}(\mathrm{CH} 3 \mathrm{COO})_{2}$ and $2.5 \% \mathrm{w} / \mathrm{v}$ drug). Extended release of drug from ZPG microparticles was observed and was also concluded that the release of ketoprofen was prolonged by the formulated ZPG microparticles which simulates intestinal fluid $(\mathrm{pH} 7.4){ }^{97}$

\section{Novel approaches for colon targeting}

\section{Osmotic controlled delivery system}

OROS is a novel delivery system for pharmaceuticals where release of drug occurs as osmotic pressure, which is produced upon the entry of the solvent. ${ }^{98}$ Elementary osmotic pump and push -pull osmotic systems are two OROSs with successful delivery requiring the application of solutes such as osmogens or osmagents apart from the drug. Additionally, osmotically active salt like $\mathrm{NaCl}, \mathrm{KCl}$, etc. maybe combined with the drug. ${ }^{99}$ OROS-CT or OROS capsules may consist of a single osmotic agent or may contain up to five or six push pull osmotic unit. ${ }^{37}$

The gelatin capsule containing the push-pull units dissolves immediately after the OROSCT is swallowed. However, the impermeable enteric coating prevents the absorption of water in the acidic environment of the stomach thereby preventing delivery of drug. The coating (Eudragit $\mathrm{S}$ 100) dissolves with increasing $\mathrm{pH}$ environment $\mathrm{pH}$ $>7$ ) in the small intestine and with the entry of water, the osmotic push compartment swells and a flowable gel is formed in the drug compartment. ${ }^{100}$ The gel is then forced out through the orifice and the rate of release is precisely controlled via the semipermeable membrane depending on the rate of water transport. For treating UC prevention of premature drug delivery is assured by designing each push pull unit to obtain a 3-4 hour post gastric delay so that release of drug starts only when a unit arrive at the colon. A constant release rate of the drug for as long as 24 hours can be maintained by OROS-CT units in the colon otherwise can deliver the drug within a period of just four hours. ${ }^{38}$ Figure 2 represent the flow diagram of OROS-CT colon targeted drug delivery system.

\section{Pressure controlled system}

Pressure-controlled colonic delivery capsules (PCDCs) is a novel technique which has overcome limitations of different basic techniques like prodrugs, $\mathrm{pH}$, time-dependent systems and microbial triggered delivery system by enhancing site specificity and feasibility of production. ${ }^{101}$ Human studies reveal that by the use of magnetoscintigraphy, PCDCs are able to deliver drug to the colon. ${ }^{102}$ PCDS bears the luminal pressure found in small intestine but collapses in high colonic pressure. This results in drug release after 3-7 hour of oral administration. PCDS are capsule shaped suppositories coated with water insoluble polymer ethyl cellulose. ${ }^{72}$

In PCDC, the drug dispersed in a suppository base, is coated with ethyl cellulose and hydrophobic polymer. The suppository base melts as it is swallowed and with increasing volume, the system resembles liquid-filled ethyl cellulose balloon (ECB) that is capable enough to resist the intestinal pressure resulting from peristalsis in the small intestine. ${ }^{25}$ As water is reabsorbed from the large intestine, the luminal pressure increases due to the ongoing peristaltic motion coupled with increasing viscous contents. ${ }^{37}$ Peristalsis induced intestinal pressure is a major factor influencing the disintegration of ECB. Hence, for PCDCs, the thickness of ethyl cellulose membrane plays a major role in delivery of drugs. ${ }^{102}$

\section{Pulsatile delivery system}

Pulsatile delivery system (PDS) is effective when delivery systems like sustained delivery cannot fulfill the requirements necessary to deliver optimum quantity of the drug within specified time. ${ }^{103}$ They are designed to deliver a drug at a controlled and predetermined rate in order to release their therapeutic agent within minimum amount of time to exert its therapeutic action instantly following programmed off release phase preventing the release of drug 3-5 hr after entering into small intestine. $^{98,104}$ Time-controlled pulsatile drug delivery systems are controlled by the system while sitespecific delivery pulsatile drug delivery systems are controlled by $\mathrm{pH}$ or enzymes in the GIT. ${ }^{105}$ Drug resistance, drug tolerance and the physiological

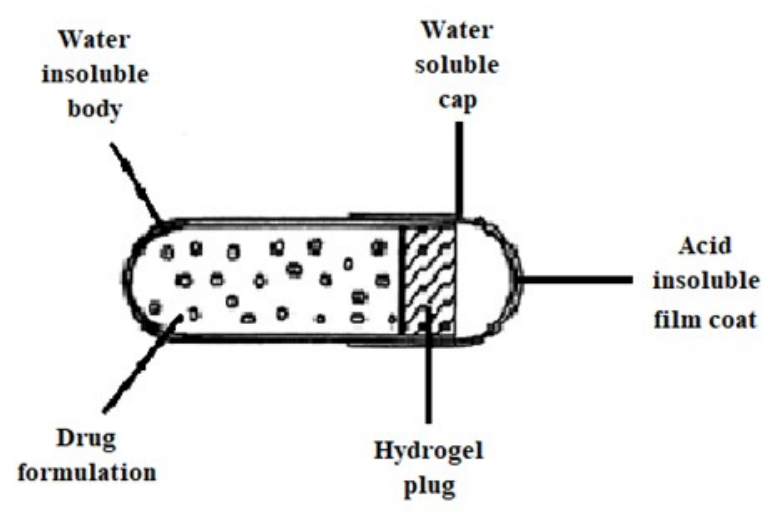

Figure 3 | Schematic design of pusincap system. 


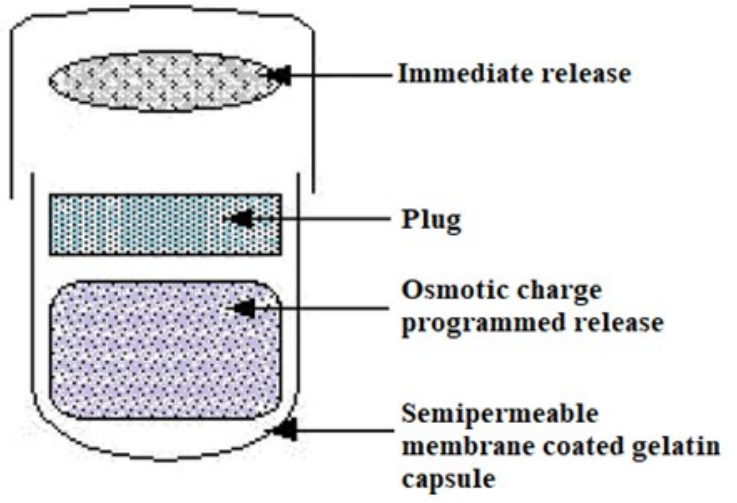

Figure 4 | Schematic design of port system.

system activated due to constant drug concentration in tissues and blood are some problems associated with PDS. ${ }^{104}$ PDS is dependent on two methods of drug deliver, i.e. pulsincap system and port system. ${ }^{37}$

Pulsincap device is made up of a half capsule body (non-disintegrating) sealed at the open end along with a hydrogel plug and is enclosed with a water-soluble cap. This capsule swells as it comes in contact with a dissolution fluid and the plug pushes itself externally to the capsule causing rapid release of the drug. ${ }^{106}$ Port system has a gelatin capsule coated with an insoluble plug that is housed in a semi permeable membrane (e.g. cellulose acetate) along with the drug formulation and an osmotically active agent. ${ }^{105}$ A coating thickness-controlled release is achieved as the capsule and dissolution fluid comes in contact and then allowing the entry of water through the semi-permeable membrane resulting in increased pressure to expel the insoluble plug after a lag time. Another advantage for this system is that it evades the second time dosing which benefits workers and school children's during working hours. ${ }^{37,107}$ Figure 3 and 4 represents the design of pulsincap and port system respectively.

\section{CODES ${ }^{\mathrm{TM}}$ technology}

CODES $^{\text {TM }}$ technology is a unique CDDS designed to steer clear of the innate difficulty related with time dependent systems or $\mathrm{pH}$ in terms of attaining feasibility of manufacturing process and in-vivo site specificity. ${ }^{100}$ Microbial-triggered CDDS and $\mathrm{pH}$ dependent approach results in CODES whose mechanism involves lactulose wherein it facilitates site specific drug release in the colon by acting as the trigger. ${ }^{38}$ The system essentially consists of a trilayered coated tablet with core drug and biodegradable polysaccharides. The tablet core is coated with an acid soluble polymer, viz. Eudragit E. This is further coated with polysaccharide such as lactulose and subsequently coated with an enteric polymer Eudragit L.

Eudragit $L$ protects the tablet from gastric enzymes and immediately dissolves after gastric emptying. Enteric coating protects the CODES below $\mathrm{pH}$ 6. But upon entry into the colon where $\mathrm{pH}$ is

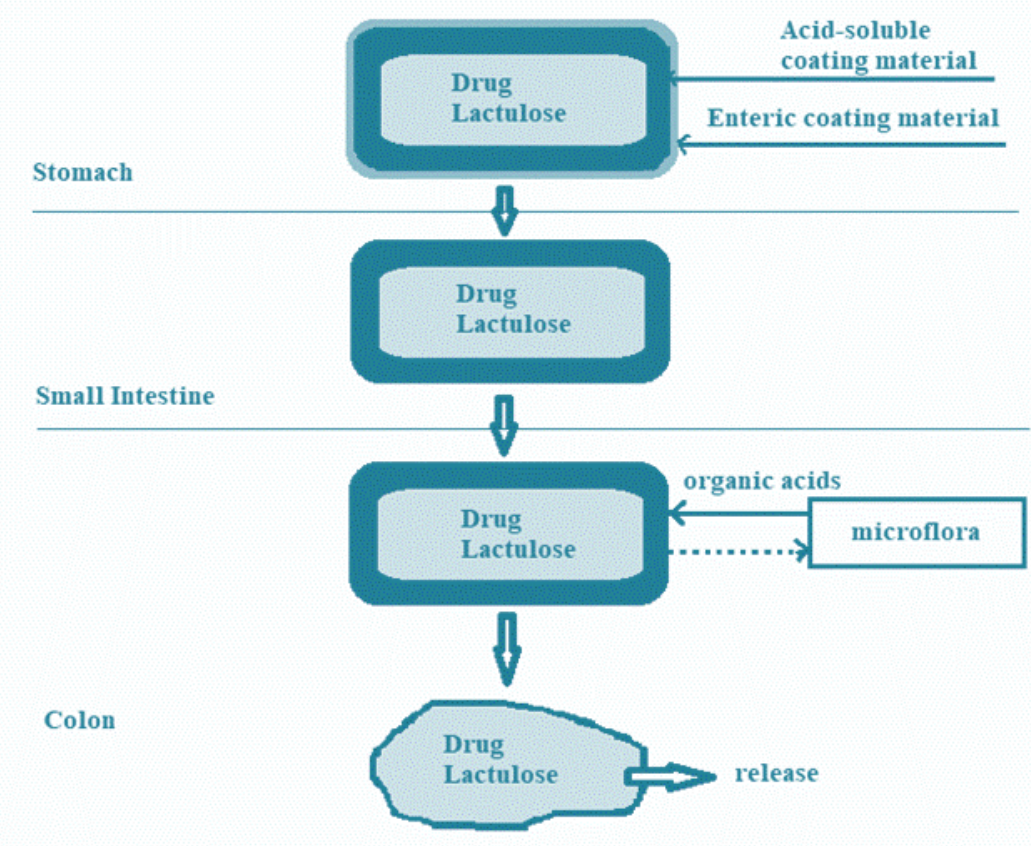

Figure 5 | Conceptual design of CODES ${ }^{T M}$ technology. 
above $\mathrm{pH} \mathrm{6,} \mathrm{the} \mathrm{polysaccharide} \mathrm{inside} \mathrm{the} \mathrm{core}$ diffuses out through the coating and gets metabolized by bacterial enzymes into organic acids which in turn lowers the $\mathrm{pH}$ to dissolve the produced Eudragit $E$ thereby releasing the drug. ${ }^{25,72,107}$ Figure 5 represents the design of CODES ${ }^{\mathrm{TM}}$ technology.

\section{Multi-particulate system}

Oral dosage forms consist of multiple small discrete units known as multi-particulate drug delivery systems. ${ }^{37}$ They usually consist of thousands of sphere-shaped particles with a diameter of 0.05 $2.00 \mathrm{~mm} .{ }^{101}$ Multi-particulate systems are known for controlled, sustained oral drug release with better chances of local targeting and increased stability in Gl conditions due to encapsulation. Particulate delivery systems show higher adhesion at the site of inflammation due to increased mucus production, enhanced permeability due to disease state and particle uptake due to a number of immune cells. This phenomenon is found to be size dependent. ${ }^{72}$ Due to their small size, uniform and safer drug absorption is observed as there is rapid distribution throughout the GIT. Residence time of particles in large intestine is associated with reduced particle size which may benefit patients with diarrhea. ${ }^{108}$ Advantages include dosage strength flexibility, optimized release for a single drug and drug combinations with minimizing food effect, exhibiting poor solubility in lower intestinal $\mathrm{pH}$, and attainment of required pharmacokinetic profile with $\mathrm{pH}$ above 8.0. ${ }^{106}$

Due to less inter subject variations, a single layered or multi-layered multi-particulate drug delivery systems has a great reproducible drug release pattern for the inflamed sites in the colon. ${ }^{88}$ Pellets, beads, granules, nanoparticles and micro particles are the type of formulations included in multi-particulate approaches. Owing to their potential benefits like decreased systemic toxicity, increased bioavailability, reduced local irritation, foreseeable gastric emptying time and prolonged residual time in the ascending colon, development of multi-particulate dosage forms is given importance over single unit systems. Due to their reduced particle size in relation to single unit dosage forms are competent to bypass the GIT smoothly, leading to less inter- and intra-subject variability. ${ }^{39,109,110}$

\section{Conclusion}

For successful delivery of drugs to the colon, one must consider into account the gastric $\mathrm{pH}$, first pass metabolism, luminal enzymatic degradation, mucin turnover and intestinal transit time which often disrupt the drug and release in the upper GiT resulting in poor colonic availability. Therefore, CTDDS is substantial for drug delivery and absorption as it offers minimizing the drawbacks outlined. However, targeting of drugs to the site specific is more likely to accomplish by employing the use of relevant polymers (pectin, chitosan, hyaluronic acid, eudragit and more) that are degraded by the existing bacterial enzymes in the colon. Various approaches such as conventional and novel approaches have been discussed in this article, having the novel approaches more precise in drug targeting. However, these approaches possess their own limitations besides their use. Therefore, pharmaceutical researchers are yet working continuously in developing more validated method to reduce its undesirable effects and increase the drug efficacy.

\section{Conflict of interest}

The authors do not have any conflict of interest.

\section{References}

1. Ordas, I., Eckmann, L., Talamini, M., Baumgart, D.C., Sandborn, W.J. (2012). Ulcerative colitis. TheLancet Journal of Gastroenterology \& Hepatology, 380, 1606-1619. DOI: https://doi.org/10.1016/S01406736(12)60150-0.

2. National Clinical Guideline Centre, (2013). Ulcerative colitis@: Management in adults, children and young people In: Clinical. Guideline: methods, Evidence and Recommendation. National institute for health and care excellence (NICE), 1297.

3. Kaur, R., Gulati, M., Singh, S.K. (2016). Role of synbiotics in polysaccharide assisted colon targeted microspheres of Mesalamine for the treatment of ulcerative colitis. International Journal of Biological Macromolecules, 11, 1-42. DOI: https:// doi.org/10.1016/j.ijbiomac.2016.11.066.

4. Gary, D.W., Frederic, D.B., James, D.L. (2013). Diet, the human gut microbiota, and IBD. Anaerobe, 3, 1-4. DOI: https://doi.org/10.1016/ j.anaerobe.2013.03.011.

5. Massimo, C., Paolo, G. (2001). Bacteria as a cause of ulcerative colitis Bacteria as the cause of ulcerative colitis. Gut Journal,48, 132-135. DOI: https://doi.org/10.1136/gut.48.1.132.

6. Luca, P., Theresa, T.P., Fabio, C., Maurizio, V. (2015). Emerging drugs for the treatment of ulcerative colitis.Expert Opinion on Emerging Drugs,14,505-521. DOI: https:// doi.org/10.1517/14728210903146882.Emerging.

7. Burger, M., Schmidt, C., Teich, N. (2015). Medical Therapy of Active Ulcerative Colitis. Visz Gastrointestinal Medical Surgery, 31, 1-9. DOI: 
https://doi.org/10.1159/000436959.

8. Peirce, C.B., Kalady, M.F. (2019). Ulcerative Proctitis and Anorectal Crohn's Disease. Fundamentals of Anorectal Surgery, 29, 531-554. DOI: https://doi.org/https://doi.org/10.1007/978-3319-65966-4_29.

9. Colitis, L.U., Proctitis, U., Regueiro, M., Loftus, E.V., Steinhart, A.H., Cohen, R.D. (2006). Clinical Guidelines for the Medical Management of Summary Statement. Lippincott Williams EWilkins, 12, 972-978.

10. Bokemeyer, B., Hommes, D., Gill, I., Broberg, P., Dignass, A. (2012). Mesalazine in left-sided ulcerative colitisø: Efficacy analyses from the PODIUM trial on maintenance of remission and mucosal healing. Journal of Crohn's E Colitis, 6, 476 -482. DOI: https://doi.org/10.1016/ j.crohns.2011.10.006.

11. Nasseri-moghaddam, S. (2012). Inflammatory Bowel Disease. Middle East Journal of Digestive Dieases, 4, 77-89.

12. Kedia, S., Ahuja, V. (2017). Epidemiology of Inflammatory Bowel Disease in India: The Great Shift East. Inflammatory Intestinal Disease, 1, 102115. DOI: https://doi.org/10.1159/000465522

13. Kameyama, H., Nagahashi, M., Shimada, Y., Tajima, Y., Ichikawa, H., (2018). Genomic characterization of colitis- associated colorectal cancer. World Journal of Surgical Oncology, 16, 160. DOI: https://doi.org/10.1186/s12957-018-1428-0

14. Lin, J., Welker, NC., Zhao, Z., Li, Y., Zhang, J., Reuss, SA., Zhang, X., Lee, H., Liu, Y., Bronner, MP. (2014). Novel specific microRNA biomarkers in idiopathic inflammatory bowel disease unrelated to disease activity. Modern Pathology, 27, 602-608. DOI: https://doi.org/10.1038/ modpathol.2013.152

15. Hanauer, S.B. (2004). Update on the etiology, pathogenesis and diagnosis of ulcerative colitis. Nature Clinical Practice Gastroenterology $\mathcal{E}$ Hepatology,1, 26-31. DOI: https://doi.org/10.1038/ ncpgasthep0031.

16. Annese, V. (2019). An update on treatment of ulcerative colitis. Expert Opinion on Orphan Drugs, 7, 295-304. DOI: https:// doi.org/10.1080/21678707.2019.1638249.

17. Ye, B., Van, L. (2015). Mesalazine preparations for the treatment of ulcerative colitis: Are all created equal? World Journal of Gastrointestinal Pharmacology Therapeutics, 6, 137-144. DOI: https:// doi.org/10.4292/wjgpt.v6.i4.137.

18. Sands, B. (2006). Immunosuppressive drugs in ulcerative colitis@: twisting facts to suit theories๑? Gut Journal, 55, 437-441. DOI: https:// doi.org/10.1136/gut.2005.078055.

19. Truelove, S., Witts, L. (1955). Cortisone in ulcerative colitis, British Medical Journal, 2, 10421048.

20. George, P., Arvind, R., Matthew, C. (2016). Rectal budesonide and mesalamine formulations in active ulcerative proctosigmoiditiso: efficacy , tolerance, and treatment approach. Clinical and Experimental Gastroenterology, 9, 125-130.

21. Zigra, P., Maipa, V., Alamanos, Y. (2007). Probiotics and remission of ulcerative colitis@: a systematic review. The Journal of Medicine, 65, 411418.

22. Amidon, S., Brown, J., Dave, S. (2015). Review Article Colon-Targeted Oral Drug Delivery Systems๑: Design Trends and Approaches. American Association of Pharmaceutical Scientists, 9, 1 -11. DOI: https://doi.org/10.1208/s12249-015-03509.

23. Seema, B., Navneet, G., Akanksha, G. (2013). Colon specific drug delivery of mesalamine using eudragit S100- coated chitosan microspheres for the treatment of ulcerative colitis. International Current Pharmaceutical Journal, 2, 42-48.

24. Bruno, S., Andre, L., Raquel, R.,Genoile, S. (2014). Epidemiology, demographic characteristics and prognostic predictors of ulcerative colitis. World Journal of Gastroenterology, 20, 9458-9467. DOI: https://doi.org/10.3748/wjg.v20.i28.9458.

25. Jose, S., Dhanya, K., Cinu, T., Litty, J., Chacko, A. (2009). Colon Targeted Drug Delivery॰: Different Approaches. Journal of Young Pharmacists, 1, 13-19. DOI: https://doi.org/10.4103/0975-1483.51869.

26. Mario, H., Mont, KV. (2013). Polymer mixtures as colon targeted drug delivery systems, Advanced Material Research,693, 2131-2136. DOI: https:// doi.org/10.4028/www.scientific.net/AMR.690693.2131

27. Anil, P., Betty, P. (2010). Colon Targeted Drug Delivery Systems: A Review on Primary and Novel Approaches, Oman Medical Journal, 25, 1-10. https://doi.org/10.5001/omj.2010.24.

28. Gadhave, M.V., Shevante, B.,Takale, A., Jadhav, S.L., Gaikwad, D.D. (2017). Formulation and Evaluation of Colon Targeted Drug Delivery of Mesalamine. International Journal of Pharmaceutical and Clinal Research, 9, 26-34. DOI: https:// doi.org/10.25258/ijpcr.v9i1.8260.

29. Swapna, A., Abdul, M., Vinay, W., Swathimutyam, P. (2011). Formulation and 
Evaluation of Mesalamine Microspheres for Colon Targeted Drug Delivery System. Journal of Pharmacy Research, 4, 1670-1672.

30. Kishori, L.D., Nilima, A.T., Paraag, S.G. (2012). Formulation and development of tinidazole microspheres for colon targeted drug delivery system. Journal of Pharmacy Research, 6, 158-165. DOI: https://doi.org/10.1016/j.jopr.2012.11.034.

31. Desi, R., Malleswari, K., Prasad, G., Pavani, G. (2013). Colon targeted drug delivery system: a review. International Journal of Pharmaceutical Science and Research, 4, 42-54.

32. Pasupathi, A., Jaykar, B. (2016). Formulation and evaluation of controlled release microspheres containing acid resistant polymers. Journal of Chemical and Pharmaceutical Sciences, 9, 679-684.

33. Vipin, K.A., Amresh, G., Shashank, C., Farheen, K. (2016). Polysaccharideø: Carrier in colon targeted drug delivery system. MIT International Journal of Pharmaceutical Sciences, 2, 1-9.

34. Ankit, D.A., Anil, S. (2019). A review on colon targeted drug delivery system, International Journal of Pharmaceutical Science and Research, 10, 47-56. DOI: https://doi.org/10.13040/IJPSR.0975-8232.10 (1).47-56.

35. Sangeetha, G., Jubaitha, B., Reddemma, S., Rajendra, Y. (2012). Colon targeted drug delivery system. International Journal of Pharmacy $\mathcal{E}$ Technology,3, 1657-1672.

36. Raghavendra, C.M., Sangamesh, AP. (2007). Development of polysaccharide-based colon targeted drug delivery systems for the treatment of amoebiasis. Drug Development and Industrial Pharmacy, 33, 255-264. DOI: https:// doi.org/10.1080/03639040600897127.

37. Sumedha, S., Chandan, K.S., Mukesh, Y., Alex, L.S. (2018). A review on novel approaches for colon targeted drug delivery systems. PharmaTutor Journal, 6, 11-22. DOI: https://doi.org/10.29161/ pt.v6.i7.2018.11.

38. Philip, A., Betty, P. (2010). Colon Targeted Drug Delivery Systems. Oman Medical Journal, 25, 1-9. DOI: https://doi.org/10.5001/omj.2010.24.

39. Jose, S., Dhanya, K., Cinu, T.A., Aleykutty, N.A. (2010). Multiparticulate system for colon targeted delivery of ondansetron. Indian Journal of Pharmaceutical Sciences, 72, 58-64. DOI: https:// doi.org/10.4103/0250-474X.62237.

40. Ghassan, Z.A., Muthanna, F.A., Mallikarjun, C., Ahmed, F.M., Omar, Z.A., Ibrahim, M.S., Azmin, M.N. (2011). Preparation and in vitro evaluation of mebeverine $\mathrm{HCl}$ colon-targeted drug delivery system. Pharmaceutical Development and Technology, 16, 331-342. DOI: https:// doi.org/10.3109/10837451003739255.

41. Rajpurohit, H., Sharma, P., Sharma, S., Bhandari, A. (2010). Polymers for Colon Targeted Drug Delivery. Indian Journal of Pharmaceutical Sciences,72, 689-696.

42. Junaid., D., Hussain, A., Amjad, K., Gul, M.K. (2017). Polymer-based drug delivery॰) the quest for local targeting of inflamed intestinal mucosa. Journal of Drug Targeting,25, 582-596. DOI: https:// doi.org/10.1080/1061186X.2017.1298601.

43. Sidramappa, M.C., Baswaraj , V.R. (2013). Formulation, in vitro drug release and in vivo human X-ray investigation of polysaccharide based drug delivery systems for targeting 5fluorouracil to the colon. Brazilian Journal of Pharmaceutical Sciences, 49, 263-273. DOI: https:// doi.org/10.1590/S1984-82502013000200008.

44. Haogang, D.,Shaoyu, L., Hongyan, Q., Chunmei, G., Xiao, B., Yuhui, W., Xin'an, W., Mingzhu, L., Xinyu, Z., Zhen, L. (2016). Co-delivery of zinc and 5-aminosalicylic acid from alginate/N-succinylchitosan blend microspheres for synergistic therapy of colitis. International Journal of Pharmaceutics, 11, 1-39. DOI: https:// doi.org/10.1016/j.ijpharm.2016.11.036.

45. Madhu, E.N., Shanker, P., Prabakaran, L., Jayveera, K.N. (2011). Novel colon specific drug delivery system: A review. International Journal of Pharmaceutical Sciences and Research,4, 22-29.

46. Momin, M., Pundarikakshudu, K.,Nagori, S.A. (2008). Design and development of mixed film of pectin: ethyl cellulose for colon specific drug delivery of sennosides and triphala. Indian Journal of Pharmaceutical Sciences, 70, 338-343. DOI: https:// doi.org/10.4103/0250-474X.42998.

47. Anuj, C., Pooja, S., Pravin, P. (2012). Eudragit S100 coated sodium alginate microspheres of naproxen sodium@: Formulation, optimization and in vitro evaluation Acta Pharm, 62, 529-545. DOI: https://doi.org/10.2478/v10007-012-0034-x.

48. Lissette, A., Dionisio, Z.S., Luis, P., Marcos, L.D. (2017). Alginate microparticles as oral colon drug delivery device: A review. Carbohydrate Polymers, 3, 1-30. DOI: https://doi.org/10.1016/ j.carbpol.2017.03.033.

49. Arvind, K.J., Vishesh, S., Meghali, B., Rajesh, V., Dhirendra, S.K. (2014). Electrosprayed inulin microparticles for microbiota triggered targeting of colon. Carbohydrate Polymers, 5, 1-27. DOI: https://doi.org/10.1016/j.carbpol.2014.05.087. 
50. Liu, Y., Zhou, H. (2015). Budesonide-loaded guar gum microspheres for colon delivery: preparation, characterization and in vitro/in vivo evaluation. International Journal of Molecular Sciences, 16, 2693 2704. DOI: https://doi.org/10.3390/ijms16022693.

51. Shrivastava, P.K., Shrivastava, A., Sinha, S.K., Shrivastava, S.K. (2013). Dextran Carrier Macromolecules for Colon-specific Delivery of 5Aminosalicylic Acid. Indian Journal of Pharmaceutical Sciences, 75, 277-283. DOI: https:// doi.org/10.4103/0250-474X.117420.

52. Prajapati, V.D., Jani, G.K., Moradiya, N.G., Randeria, N.P., Nagar, B.J. (2013). Locust bean gum॰: A versatile biopolymer. Carbohydrate Polymers, 94, 814-821. DOI: https://doi.org/10.1016/ j.carbpol.2013.01.086.

53. Ramasamy, T., Subbaih, K.U., Shanmugam, S., Ruttala, H. (2012). Formulation and evaluation of chondroitin sulphate tablets of aceclofenac for colon targeted drug delivery. Iranian Journal of Pharmaceutical Research, 11, 465-479.

54. Carla, C., Amparo, N., Octavio, D.S., Matilde, M.S., Anna, M.F. (2014). Chitosan - xanthan gum microparticle-based oral tablet for colon-targeted and sustained delivery of quercetin. Journal of Microencapsulation, 6, 1-6. DOI: https:// doi.org/10.3109/02652048.2014.913726.

55. Huang, G., Huang, H. (2018). Application of hyaluronic acid as carriers in drug delivery. Drug Delivery, 25, 766-772. DOI: https:// doi.org/10.1080/10717544.2018.1450910.

56. Cetin, M., Atila, A., Kadioglu, Y. (2010). Formulation and in vitro characterization of Eudragit ${ }^{\circledR} \quad$ L100 and Eudragit ${ }^{\circledR} \quad$ L100-PLGA nanoparticles containing diclofenac sodium. American Association of Pharmaceutical Scientists, 11, 1250-1256. DOI: https://doi.org/10.1208/s12249-010 -9489-6.

57. Ahmadi, E., Sadrjavadi, K., Mohammadi, G., Fattahi, A. (2018). De-Esterified Tragacanth Microspheres Loaded into Eudragit S-100 Coated Capsules for Colon-Targeted Delivery. Iranian Journal Pharmaceutical Research, 17, 470-479.

58. Jaweed, L., Dilshad, H., Sarwar, G. (2019). Application of Eudragit RS 30D as a Potential Drug Release Retardant of Acetaminophen and Caffeine for Prolonged Duration of Comfort. International Journal of Polymer Science,11, 1-8. DOI: https://doi.org/https:// doi.org/10.1155/2019/3830670.

59. Davaran, S., Rashidi, M., Khani, A. (2007). Synthesis of Chemically Cross-Linked
Hydroxypropyl Methyl Cellulose Hydrogels and their Application in Controlled Release of 5Amino Salicylic Acid. Drug Development and Industrial Pharmacy, 33, 881-887. https://doi.org/ doi:10.1097/00054725-200705005-00062.

60. Pal, K., Allan, T.P., Derick, R. (2009). Biopolymers in Controlled-Release Delivery Systems. Modern Biopolymer Science, 1, 519-557. DOI: https:// doi.org/10.1016/B978-0-12-374195-0.00016-1.

61. Dan, M.G., Mihai, G.A., Everard, B.L., Bejenaru, C. (2016). Natural and synthetic polymers for drug delivery and targeting, In: Nanobiomaterials in Drug Delivery. Application of. Nanobiomaterials, Elsevier Inc, 229-284. DOI: https://doi.org/10.1016/B978-0323-42866-8.00008-3.

62. Deepak, N.K., Amit, B., Ripandeep, K., Ruchi, S., Gurvinder, K., Sanju, D. (2015). PLGA: A unique polymer for drug delivery. Therapeutic Delivery, 6, 41-58. DOI: https://doi.org/10.4155/tde.14.91.

63. Jarkko, R., Hanna, K., Tycho, H., Reza, O., Dooman, O., Tomi, J., Jouko, S. (2008). Prodrugs: Design and clinical applications. Drug Discovery, 7, 255-270. DOI: https://doi.org/10.1038/nrd2468.

64. Vikram, L., Sandeep, S., Vimal, A. (2012). Prodrug: Approach to better drug delivery. International Journal of Pharmaceutical Research, 4, 15-21.

65. Apninder, K., Amarjeet, K., Vishav, P.K., Manpreet, K., Ramchandra, S.M., (2014). Polymeric Drug Delivery Approaches for Colon Targeting: A Review. Drug Delivery Letters, 4, 38$48 . \quad$ DOI: https:// doi.org/10.2174/22103031113036660017.

66. Kratz, F., Muller, IA., Ryppa, C., Warnecke, A. (2008.) Prodrug strategies in anticancer chemotherapy. ChemMedChem,3, 20-53. DOI: https://doi.org/10.1002/cmdc.200700159.

67. Longquin, H. (2005). Prodrug Approaches to Drug Delivery In: Drug Deliv. Princ. Appl., Binghe Wan John Wiley \& Sons.Inc, 125-165. DOI: https:// doi.org/10.1002/0471475734.ch8.

68. Anas, N., Rafik, K. (2019). The prodrug approach in the era of drug design. Expert Opinion on Drug Delivery, 16, 1-5. DOI: https:// doi.org/10.1080/17425247.2019.1553954.

69. Suneela, SD. (2014). Colon-specific prodrugs of 4aminosalicylic acid for inflammatory bowel disease. World Journal of Gastroenterology, 20, 35643571. DOI: https://doi.org/10.3748/ wjg.v20.i13.3564.

70. Markovic, M., Dahan, A., Keinan, S., Kurnikov, I., Aponick, A., Zimmermann, E.M., Ben-Shabat, S. (2019). Phospholipid-based prodrugs for colon- 
targeted drug delivery: Experimental study and in -silico simulations. Pharmaceutics, 11, 1-16. DOI: https://doi.org/10.3390/pharmaceutics11040186.

71. Lee, S.H., Bajracharya, R., Min, J.Y., Han, J.W., Park, B.J., Han, H.K. (2020). Strategic approaches for colon targeted drug delivery: An overview of recent advancements. Pharmaceutics, 12, 1-19. DOI: https://doi.org/10.3390/pharmaceutics12010068.

72. Anisha, A.D., Munira, M., Sujata, P.S., Upasna, S., (2016). Colonic Drug Targeting Approaches for Treatment of Inflammatory Bowel Disease. SM Journal of Gastroenterology and Hepatology, 1, 1-17.

73. Janarthanan, P., Anand, K.V., Cally, O., Xian, J.L. (2016). Biodegradable Polysaccharides for Controlled Drug Delivery. Chempluschem,81, 504514. DOI: https://doi.org/10.1002/cplu.201600112.

74. Chourasia, M.K., Jain, S.K., (2004). Polysaccharides for Colon Targeted Drug Delivery. Drug Delivery, 11, 129-148. DOI: https:// doi.org/10.1080/10717540490280778.

75. Miao, T., Wang, J., Zeng, Y., Liu, G., Chen, X. (2018). Polysaccharide-Based Controlled Release Systems for Therapeutics Delivery and Tissue Engineering $\odot$ : From Bench to Bedside. Advanced Science, 17, 1-32. DOI: https://doi.org/10.1002/ advs.201700513.

76. Zhang, L., Sang, Y., Feng, J., Li, Z., Zhao, A. (2016). Polysaccharide-based micro / nanocarriers for oral colon-targeted drug delivery. Journal of Drug Targeting, 24, 579-589. DOI: https:// doi.org/10.3109/1061186X.2015.1128941.

77. Bingchao, D., Mengxia, L., Ying, S., Siwei, Z., Xiaojuan, X. (2019). Orally Delivered Antisense Oligodeoxyribonucleotides of TNF- $\alpha$ via Polysaccharide-Based Nanocomposites Targeting Intestinal Inflammation. Advanced Healthcare Materials, 18, 1-12. DOI: https://doi.org/10.1002/ adhm.201801389.

78. Duan, H., Lu, S., Gao, C., Bai, X., Qin, H., Wei, Y. (2016). Colloids and Surfaces B๑: Biointerfaces Mucoadhesive microparticulates based on polysaccharide for target dual drug delivery of 5aminosalicylic acid and curcumin to inflamed colon. Colloids and Surfaces B: Biointerfaces, 5, 510 519. DOI: https://doi.org/10.1016/ j.colsurfb.2016.05.038.

79. Sachin, K.S., Ankit, K.Y., Prudhviraj, G., Monica, G., Puneet, K., Yogyata, V. (2015). A novel dissolution method for evaluation of polysaccharide based colon specific delivery systems: A suitable alternative to animal sacrific. European Journal of Pharmaceutical Sciences, 73, 72-
80. DOI: https://doi.org/10.1016/j.ejps.2015.03.012.

80. Prudhviraj, G., Vaidya, Y., Kumar, S., Kumar, A., Kaur, P., Gulati, M., Gowthamarajan, K. (2015). Effect of co-administration of probiotics with polysaccharide based colon targeted delivery systems to optimize site specific drug release. European Journal of Pharmaceutics and Biopharmaceutics, 6, 1-9. DOI: https:// doi.org/10.1016/j.ejpb.2015.09.012.

81. Zhang, S., Lange,r R.,Traverso, G. (2017). Nanoparticulate drug delivery systems targeting inflammation for treatment of inflammatory bowel disease. Nano Today, 16, 82-96. DOI: https:// doi.org/10.1016/j.nantod.2017.08.006.

82. Gupta, B., Soon, C., Jong, Y., Kim, O. (2017). Solid matrix-based lipid nanoplatforms as carriers for combinational therapeutics in cancer. Journal of Pharmaceutical Investigation, 47, 461-473. DOI: https://doi.org/10.1007/s40005-017-0337-5.

83. Harel, E., Rubinstein, A., Nissan, A., Khazanov, E., Milbauer, M.N. (2011). Enhanced Transferrin Receptor Expression by Proinflammatory Cytokines in Enterocytes as a Means for Local Delivery of Drugs to Inflamed Gut Mucosa. Target for Local Delivery to Inflammation, 6, 1-12. DOI: https://doi.org/10.1371/journal.pone.0024202.

84. Xiao, B., Laroui, H., Viennois, E., Ayyadurai, S., Charania, M.A., Zhang, Y., Zhang, Z., Baker, M.T., Zhang, B., Gewirtz, A.T., Merlin, D. (2012). Nanoparticles with Surface Antibody Against CD98 and Carrying CD98 Small Interfering RNA Reduce Colitis in Mice. Gastroenterology, 23, 1-7. DOI: https://doi.org/10.1038/jid.2014.371.

85. Ghosh, D., Peng, X., Leal, J., Mohanty, R. (2016). Peptides as drug delivery vehicles across biological barriers. Journal of Pharmaceutical Investigation, 176, 139-148. DOI: https:// doi.org/10.1016/j.physbeh.2017.03.040.

86. Ren, Y., Mu, Y., Song, Y., Xie, J., Yu, H., Gao, S., Li, S., Peng, H., Zhou, Y., Lu, W. (2016). A new peptide ligand for colon cancer targeted delivery of micelles. Drug Delivery, 23, 1763-1772. DOI: https://doi.org/10.3109/10717544.2015.1077293.

87. Choi, M., Cao, J., Lee, Y., Ikram, M. (2015). Colontargeted delivery of budesonide using dual $\mathrm{pH}$ and time-dependent polymeric nanoparticles for colitis therapy. Drug Design, Development and Therapy, 9, 3789-3799. DOI: https://doi.org/http:// dx.doi.org/10.2147/DDDT.S88672.

88. Rashid, M., Kaur, V., Hallan, S.S., Sharma, S., Mishra, N. (2014). Microparticles as Controlled Drug Delivery Carrier for the treatment of 
Ulcerative Colitis@: A brief review. Saudi Pharmaceutical Journal, 10, 1-51. DOI: https:// doi.org/10.1016/j.jsps.2014.10.001.

89. Zeeshan, M., Ali, H., Khan, S., Khan, S.A.,Weigmann, B. (2019). Advances in orallydelivered $\mathrm{pH}$-sensitive nanocarrier systems; an optimistic approach for the treatment of inflammatory bowel disease. International Journal of Pharmaceutics, 12, 201-214. DOI: https:// doi.org/10.1016/j.ijpharm.2018.12.074.

90. Arvind, G., Aviral, J., Ashish, J., Ankit, J., Sanjay, K.J. (2016). Insight to drug delivery aspects for colorectal cancer. World Journal of Gastroenterology, 22, 582-599. DOI: https://doi.org/10.3748/ wjg.v22.i2.582.

91. Fahima, M.H., Dalia, SS., Mohamed, N., Reem, R. (2013). In Vitro and In Vivo Evaluation of Combined Time and pH- Dependent Oral Colonic Targeted Prednisolone Microspheres. British Journal of Pharmaceutical Research, 3, 420-434. DOI: https://doi.org/10.9734/bjpr/2014/3195.

92. Akhgari, A., Sadeghi, F., Garekani, H.A. (2006). Combination of time-dependent and $\mathrm{pH}$ dependent polymethacrylates as a single coating formulation for colonic delivery of indomethacin pellets. Internaltional Journal of Pharmaceutics,5, 137 -142. DOI: https://doi.org/10.1016/ j.ijpharm.2006.05.011.

93. Chourasia, M.K., Jain, S.K. (2003) Pharmaceutical approaches to colon targeted drug delivery systems. Journal of Pharmacy and Pharmaceutical Sciences, 6, 33-66.

94. Patel, M.M. (2014). Getting into the colon: Approaches to target colorectal cancer. Expert Opinion on Drug Delivery, 11, 1343-1350. DOI: https://doi.org/10.1517/17425247.2014.927440.

95. Chickpetty, M.S., Baswaraj, R., Kumar, G.S. (2011). Development of Novel Combined Time and $\mathrm{pH}$ Dependent based Drug Delivery Systems for Targeting 5-Fluorouracil to the Colon. Current Drug Delivery,8, 566-574.

96. Nidhi, Rashid, M., Kaur, V., Hallan, S.S., Sharma, S., Mishra, N. (2016). Microparticles as controlled drug delivery carrier for the treatment of ulcerative colitis: A brief review. Saudi Pharm J, 24, 458-472. DOI: https://doi.org/10.1016/ j.jsps.2014.10.001.

97. El-gibaly, I. (2002). Oral delayed-release system based on Zn-pectinate gel (ZPG) microparticles as an alternative carrier to calcium pectinate beads for colonic drug delivery. International Journal of Pharmaceutics, 232232, 199-211. DOI: https:// doi.org/doi:10.1016/s0378-5173(01)00903-6.

98. Singh N, \& Khanna RC (2012) Colon targeted drug delivery systems - A Potential Approach PHARMA Innov 1(1) 40-47.

99. Kushal, M., Monali, M., Durgavati, M., Mittal, P., Umesh, S., Pragna, S. (2013). Oral controlled release drug delivery system: an overview. International Research Journal of Pharmacy, 4, 70-76. DOI: https://doi.org/10.7897/2230-8407.04312.

100. Ratnaparkhi Mukesh P., Somvanshi Fattesingh U., Pawar Sham A., Chaudhari Shilpa P., Gupta Jyoti P. (2013). Colon targeted drug delivery system. International Journal of Pharmaceutical Sciences Research and Reviews, 2, 33-42.

101. Jaiswal, M., Lanjhiyana, S. (2019). A Critical Review on Colon Targeted Drug Delivery Systems for management of IBD. International Journal of Pharmaceutical Sciences and Research, 10, 985-992. DOI: $\quad$ https://doi.org/10.13040/IJPSR.0975-8232.10 (3).985-92.

102. Jeong, Y., Ohno, T., Hu, Z., Yoshikawa, Y. (2001). Evaluation of an intestinal pressure-controlled colon delivery capsules prepared by a dipping method. Journal of Controlled Release, 71, 175-182.

103. Mehta, M.B., Nathwani, S., Soniwala, M.M., Pharmaceutics, M.P. (2014) Pulsatile drug delivery system®: advanced and novel approach. Mintage Journal of Pharmaceutical and Medical Sciences, 3, 411.

104. Patil, C.U., Talele, A.N., Chamadia, A.R. (2016). A review on floating pulsatile tablets novel approach for oral drug delivery systems. Journal of Pharmaceutical Sciences and Bioscientific Research, 6, 356-364.

105. Kumar, A., Aggarwal, G., Harikumar, S.L. (2015). Colon specific drug delivery by ph sensitive polymers \& pulsatile drug delivery system. Indo Global Journal of Pharmaceutical Sciences, 5, 6-11.

106. Jain, D., Raturi, R., Jain, V., Bansal, P., Singh, R. (2011). Recent technologies in pulsatile drug delivery systems. Biomatter, 1, 57-65. DOI: https:// doi.org/10.4161/biom.1.1.17717.

107. Patil, N.D., Bari, M.M., Barhate, S.D. (2013). A review on novel approach pulsatile drug delivery system. International Journal of Pharmaceutical Sciences Review and Research, 21, 209-222.

108. Sardo, H.S., Saremnejad, F., Bagheri, S., Akhgari, A. (2019). A review on 5-aminosalicylic acid colontargeted oral drug delivery systems. International Journal of Pharmaceutics, 1, 367-379. DOI: https:// doi.org/10.1016/j.ijpharm.2019.01.022. 
109. Kushwaha, P., Fareed, S., Nanda, S., Mishra, A. (2011). Design \& fabrication of tramadol hcl loaded multiparticulate. Journla of Chemical and Pharmaceutical Research, 3, 584-595. DOI: https:// doi.org/10.13040/IJPSR.0975-8232.10(3).985-92.

110. De Alencar, R.G., De Oliveira, A.C., Lima, E.M., Sergio, M., Taveira, S.F., Marreto, R.N. (2017). Compacted multiparticulate systems for colonspecific delivery of ketoprofen. AAPS PharmSciTech, 6, 1-9. DOI: https://doi.org/10.1208/ s12249-016-0700-2. 